\title{
ESPECIFICIDADES DO PAGAMENTO DE ROYALTIES PELA USINA HIDRELÉTRICA BINACIONAL DE ITAIPU AOS MUNICÍPIOS PARAGUAIOS
}

Nilse Girotto ${ }^{1}$

Edson dos Santos Dias ${ }^{2}$

\begin{abstract}
Resumo: O objetivo central deste artigo é apresentar a normatização e os limites que envolvem o repasse do pagamento na forma de compensação (chamado de royalties) aos municípios paraguaios atingidos pela formação do reservatório da Usina Hidrelétrica Binacional de Itaipu. O referencial teórico pautou-se no entendimento do papel do Estado no processo histórico geográfico de implantação desse megaprojeto que resultou em profunda transformação espacial na zona de fronteira entre os dois países. A metodologia utilizada envolveu a pesquisa bibliográfica, levantamento de dados e da legislação, trabalho de campo e aplicação de entrevista.
\end{abstract}

Palavras-chave: Estado. Megaprojetos. Compensação financeira.

\section{SPECIFICITIES OF ROYALTIES PAYMENT BY ITAIPU BINATIONAL HYDROELECTRIC POWER PLANT TO PARAGUAYAN MUNICIPALITIES}

\begin{abstract}
The main purpose of this manuscript is to present the standardization and limits that involve the payment transference in a form of compensation (called royalties) to the Paraguayan municipalities affected by the reservoir formation of Itaipu Binational Hydroelectric Power Plant. The theoretical framework was guided on the role understanding of the State in the historical geographical process of implantation of this megaproject that resulted in a deep spatial transformation in the border area between the two countries. The methodology used involved bibliographic research, data and legislation survey, fieldwork and interview application.
\end{abstract}

Keywords: State; Megaprojects; Financial compensation

\section{ESPECIFICIDADES DEL PAGO DE ROYALTIES POR LA PLANTA HIDROELÉCTRICA BINACIONAL DE ITAIPU A LAS MUNICIPALIDADES PARAGUAYAS}

Resumen: El objetivo principal de este artículo es presentar la normatización y los límites que implican la transferencia de pago en forma de compensación (llamados royalties) a los municipios paraguayos afectados por la formación del embalse de la Central Hidroeléctrica Binacional de Itaipu. El marco teórico se basó en la comprensión del papel del Estado en el proceso histórico geográfico de implantación de este megaproyecto que resultó en una profunda transformación espacial en la

\footnotetext{
1 Universidade Estadual do Oeste do Paraná (UNIOESTE), M.C.Rondon, Brasil. nilsesinha@yahoo.com.br, https://orcid.org/0000-0001-8209-1089

2 Universidade Estadual do Oeste do Paraná (UNIOESTE), Programa de Pós-Graduação em Geografia da UNIOESTE (Campus de M.C.Rondon), Brasil. edias88@yahoo.com.br, https://orcid.org/0000-0001-7323-8499
} 
zona fronteriza entre los dos países. La metodología utilizada incluyó la investigación bibliográfica, la recopilación de datos y legislación, el trabajo de campo y la aplicación de entrevista.

Palabras clave: Estado. Megaproyectos. Compensación financeira.

\section{Introdução}

Neste artigo, toma-se como referência o Estado em um papel fundamental e estratégico no intermédio da atuação do capital e das grandes corporações em seu território, através da instalação de megaprojetos - empreendimentos com intensa ação de capital e ampliação dos lucros - os quais são justificados através do uso massivo de propaganda midiática, sendo fundamentais para o crescimento e 0 desenvolvimento econômico de um país, região ou cidade.

Ao discutir a integração energética, Silva (2015) avalia a atuação do Estado como responsável por controlar a produção de energia, ao propiciar a infraestrutura necessária, flexibilizar leis, facilitar e garantir o consumo do mercado nacional, bem como possibilitar os arranjos para a ampliação do mercado externo. Os governos mais vulneráveis economicamente tendem a perder poder interno em suas decisões diante das exigências do capital.

No mundo globalizado, o Estado cumpre função estratégica para o desenvolvimento do capitalismo, ao criar a infraestrutura necessária para sua circulação dentro do território, estabelecendo regras para atrair o capital. Conforme Castro (2005, p. 238), "[...] embora o capital esteja livre para voar, é o Estado quem fornece as condições para o seu pouso, revalorizando o território para manter antigos investimentos ou para atrair novos."

Em conformidade com Castro, Silva (2015, p. 448) reitera que a "[...] reprodução e a acumulação do capital só é possível com a presença ativa do Estado, que media e subsidia de diversas formas a apropriação e a exploração do trabalho e da natureza". A partir dessas referências, parte-se do pressuposto de que o Estado, mesmo permeado por contradições e disputas de projetos, ainda possui um papel estratégico, tanto no que se refere às ações quanto às regulamentações das formas de organizações econômicas e sociais estruturantes, ao contrário de tendências ultraliberais que preconizam um "Estado mínimo".

Para os agentes públicos ou privados, responsáveis pela implantação dos grandes empreendimentos de infraestrutura, o local restringe-se ao ambiente de instalação da obra, e a empresa apresenta-se como articuladora do progresso 
advindo com a construção e a operação, desconsiderando ou minimizando a organização sócio-espacial anterior, a dinâmica regional e os impactos decorrentes da instalação.

Dentro do contexto de instalação de megaprojetos, a usina hidrelétrica de Itaipu apresenta-se de forma exemplar. Trata-se de uma empresa binacional, o que Ihe confere uma condição institucional muito específica diante das legislações dos dois países parceiros em sua construção, no caso, Brasil e Paraguai, que precisam negociar as deliberações relacionadas à empresa, conforme o Tratado de Itaipu, assinado em 1973. Entre essas questões, encontra-se o repasse financeiro, os denominados royalties, a título de compensação pela formação do grande reservatório da usina e por suas implicações sociais e ambientais.

A literatura consultada sobre o repasse de royalties para os municípios atingidos no lado brasileiro, em decorrência da construção da Usina Hidrelétrica Binacional de Itaipu, indica a elaboração de diversos estudos acadêmicos e técnicos que possuem esse tema como escopo central ${ }^{3}$. Contudo, o objetivo do presente artigo é de compreender as particularidades envolvidas com a normatização do repasse do pagamento de compensação aos municípios paraguaios, um recorte geográfico negligenciado nas análises feitas por pesquisadores brasileiros.

Com o propósito de atingir o objetivo previsto, a pesquisa foi realizada a partir de um estudo bibliográfico, documental e de campo. Documentos e regulamentações disponibilizados pela Usina de Itaipu, através do seu site oficial, foram consultados a fim de levantar os valores de repasse dos royalties, além dos tratados e dos acordos que regem a empresa. Enfim, o marco legal que regulamenta e normatiza o pagamento dessa compensação no território brasileiro e paraguaio, bem como suas alterações.

Antes de abordar as principais questões envolvidas no repasse desse tipo de recurso para os municípios paraguaios, faz-se a apresentação do contexto histórico que resultou na opção (geo)política, e não somente técnica, para a construção de uma usina de grande porte em uma área de fronteira, bem como os seus desdobramentos diplomáticos na forma de acordos institucionais.

\footnotetext{
${ }^{3}$ Para os interessados no estudo sobre a aplicação dos royalties repassados pela Itaipu aos municípios no Brasil, sugere-se a consulta às seguintes referências, as quais representam uma pequena amostra dos vários trabalhos desenvolvidos: Iwake (2005); Oliveira (2008); Rocha (2012); Lorenzon (2016); Higa (2016); Martins; Costa e Santos (2018) e Thibes (2019).
} 
Acordos e tratados para a construção da Usina Hidrelétrica Binacional de Itaipu

O desenvolvimento do setor industrial no Brasil começou a ganhar maior destaque a partir da década de 1930, mas se intensificou significativamente em período posterior, impulsionado por fatores econômicos, políticos e sociais que ocorriam nos planos externo e interno, inclusive 0 acelerado processo de urbanização pelo qual passou o país a partir das décadas de 1960 e 1970.

A gradativa ampliação dos parques industriais e o crescimento das cidades tornou estratégica a avaliação sobre o planejamento relacionado à política energética no Brasil. Neste cenário, foi tomando forma, nos planos previstos para a ampliação da oferta de energia, a importância da Bacia do Prata e do Rio Paraná, como área para a instalação de hidrelétricas, devido ao seu potencial hídrico e relevo favorável.

No entanto, sendo o Rio Paraná utilizado como marco divisor entre o Brasil e o Paraguai, a decisão sobre o melhor local para a construção de uma grande usina demandou anos de discussões entre os representantes dos governos dos dois países. Como outro fator complicador, a Argentina reivindicava participação nos debates, alegando que seu potencial hídrico na Bacia da Prata seria afetado, devido à localização de seu território à jusante da construção.

A tensão geopolítica entre os três países - Brasil, Paraguai e Argentina - foi outro fator influenciador na escolha do local para a construção da Usina de Itaipu. Localizado entre as potências Brasil e Argentina, sem saída para o mar e tentando se impor para manter a soberania nacional, o Paraguai adotou uma política denominada por Rolon (2010) de "pendular". Como característica desse tipo de política, quando the era mais favorável, o governo paraguaio negociava com a Argentina. Posteriormente, sob a ditadura de Stroessner, houve uma aproximação geopolítica maior com o Estado brasileiro. De outro lado, Brasil e Argentina disputavam o poder hegemônico na América do Sul, defendendo e negociando conforme seus respectivos interesses nacionais, porém, com ênfase nas parcerias comerciais.

Após a Guerra da Tríplice Aliança (1864-1870), o Paraguai permaneceu por um longo período submetido aos países vencedores. No entanto, a vitória sobre a Bolívia na Guerra do Chaco, em 1932, renovou o vigor e a autoestima paraguaia, 
que retomou a política externa de aproximação com os Estados Unidos, Brasil e Argentina, adotando a política pendular (ROLON, 2010).

A zona de fronteira formada pelo rio Paraná, envolta em questões geopolíticas e de disputas fronteiriças entre o Brasil e o Paraguai, apresentava os melhores resultados técnicos para a implantação de uma grande hidrelétrica, não se definindo a priori o local específico da possível construção, que poderia ser em algum lugar a partir das Sete Quedas, em Guaíra, chegando até Foz do Iguaçu, ambos municípios paranaenses.

$\mathrm{Na}$ década de 1950, iniciaram-se os estudos para o aproveitamento dos recursos hídricos dos saltos de Sete Quedas, contando com diferentes projetos, todos elaborados para a possível construção da hidrelétrica somente como empresa brasileira, desconsiderando-se a participação do Paraguai. Dentre os projetos, destaca-se o do engenheiro Sylvestre Souza, elaborado em 1961, o qual previa a instalação de uma usina em Guaíra sem comprometer as quedas d'água do ponto turístico. A construção ocorreria por meio de um desvio do rio dentro do território brasileiro, antes de chegar nas quedas (LIMA, 2006).

Desses estudos, surgiram relatórios apontando que o aproveitamento das quedas do rio Paraná era viável para o país, porém, aqueles não apresentavam planos detalhados para uma construção. O projeto de maior relevância foi o do escritório de Octávio Marcondes Ferraz, que previa a construção de um canal com o objetivo de desviar o curso do rio, preservando as quedas, aproveitando os cânions abaixo das Sete Quedas e favorecendo a navegação (LIMA, 2006).

Nosso projeto constava de uma usina de dez milhões de quilowatts, instalada em Porto Mendes Gonçalves, do lado brasileiro. O fato de a usina ter sido projetada exclusivamente em território brasileiro deveu-se apenas a uma questão técnica; achei que seria a melhor solução, porque assim a usina se livrava da inundação da cachoeira na época das cheias, adquiria uma potência bastante grande e era de fácil execução (FERRAZ, 1993, p. 166).

Quando questionado se o projeto desenvolvido por seu escritório não eliminava os direitos do Paraguai, o engenheiro Ferraz respondeu: "sou um técnico, fui chamado para resolver um problema técnico. A melhor solução, a meu ver, foi a que dei. Os direitos do Paraguai são uma questão política a ser resolvida entre os dois governos" (FERRAZ, 1993, p. 166).

Esse projeto reascendeu a hostilidade e o debate sobre a fronteira entre Brasil e Paraguai, não somente quanto ao aproveitamento dos recursos hídricos do 
rio Paraná, mas também por envolver a área dos saltos das Sete Quedas, em disputa pelos dois países. O Tratado de Limites de 1872, assinado entre os países, assim definia a questão:

O territorio do Imperio do Brasil divide-se com o da Republica do Paraguay pelo alveo do rio Paraná, desde onde começam as possessões brasileiras na foz do Iguassú até o Salto Grande das Sete Quedas do mesmo rio Paraná.

Do Salto Grande das Sete Quedas continúa a linha divisoria pelo mais alto da Serra de Maracajú até onde ella finda. Dahi segue em linha recta, ou que mais se the aproxime, pelos terrenos mais elevados a encontrar a Serra Amambahy. Prosegue pelo mais alto desta Serra até a nascente principal do rio Apa, e baixa pelo alveo deste até sua foz na margem oriental do rio Paraguay (BRASIL, DECRETO № 4.911, 1872).

Tanto o governo paraguaio quanto o brasileiro consideravam a área dos saltos das Sete Quedas como pertencentes aos seus respectivos territórios. Em um encontro informal, no dia 19 de janeiro de 1964, posteriormente comunicado à imprensa, os então presidentes do Brasil e do Paraguai, João Goulart e Alfredo Strossner, respectivamente, mantiveram uma conversa na fazenda particular do presidente brasileiro, situada no pantanal mato-grossense, na divisa com o Paraguai. No comunicado divulgado pelos mandatários de ambos os países, dentre outros assuntos, reiteraram a intenção da construção de uma usina em parceria entre os países, denominada de Sete Quedas (JORNAL DO BRASIL, 1964).

Resultou deste encontro, também, o compromisso de utilização das águas fronteiriças somente mediante acordo entre ambos os países. Esse compromisso foi posteriormente formalizado pela Ata do Iguaçu, em 1966, já em um contexto político no qual havia transcorrido o golpe militar, mas o interesse na construção da megausina permanecia constante.

O formato de negociação, com a escolha de cidades em ambos os países para firmar a Ata de Iguaçu, sendo Foz do Iguaçu, no Brasil, e Porto Presidente Stroessner (atual Ciudad del Este), no Paraguai, demonstra a intenção de equilíbrio das soberanias nacionais, resultante do clima hostil e inseguro que pairava nos ânimos brasileiro e, principalmente, paraguaio.

Essa animosidade entre os países decorria dos projetos de desvio das águas do rio Paraná para a construção de uma usina unicamente brasileira. Também é preciso considerar que, apesar de passados cem anos do conflito envolvendo a 
Tríplice Aliança contra o Paraguai, o assunto continuava recorrente, abordado pelas mídias, pela população e pelo governo paraguaio ${ }^{4}$.

Ficou acordada, com a Ata de Iguaçu, a intenção de sanar possíveis problemas existentes e proclamar, de comum acordo, o uso condômino dos recursos hidráulicos dos saltos grandes de Sete Quedas, conforme expresso na ata assinada em 1966:

\begin{abstract}
CONCORDARAM em estabelecer, desde já, que a energia elétrica eventualmente produzida pelos desníveis do rio Paraná, desde e inclusive o Salto Grande de Sete Quedas ou Salto do Guaíra até a foz do rio Iguaçu, será dividida em partes iguais entre os dois países, sendo reconhecido a cada um deles o direito de preferência para a aquisição desta mesma energia a justo preço, que será oportunamente fixado por especialistas dos dois países, de qualquer quantidade que não venha a ser utilizada para 0 suprimento das necessidades do consumo do outro país. (BRASIL, ATA DE IGUAÇU, 1966).
\end{abstract}

A Ata do Iguaçu teve o objetivo de firmar interesses comuns e evitar desgaste nas relações externas, "apesar da Ata das Cataratas possuir sua incerteza [...] foi um documento essencialmente político, direcionado a pôr fim às questões de limites, pois supunha que a área litigiosa ficaria submersa pelo futuro reservatório" (LIMA, 2006, p. 143). Essa primeira tratativa foi sistematizada e normatizada com o Tratado de Itaipu, assinado em 1973, o qual constituiu um instrumento jurídico de cooperação econômica internacional do uso dos recursos hídricos na Bacia do Prata.

Em 1967, no ano seguinte à assinatura da Ata de Iguaçu, também chamada de Ata das Cataratas, foi designada uma comissão mista a fim de iniciar os estudos para a implantação da usina. Este grupo, formado por brasileiros e paraguaios, teve a incumbência de implementar os termos do acordo.

Devido a localização à jusante do ponto previsto para a construção de Itaipu, o governo argentino passou a criticar a construção, por acreditar que haveria impactos na utilização dos seus recursos hídricos, com a diminuição da velocidade e da vazão do rio, questionando também o fato de não ter sido consultado sobre a construção da usina. Para sanar essas divergências, ocorreu a assinatura do Tratado da Bacia do Prata, com a participação do Brasil, da Argentina, da Bolívia, do

\footnotetext{
${ }^{4}$ Para maiores informações sobre o litígio fronteiriço entre os dois países consultar o estudo de Barros (2012).
} 
Paraguai e do Uruguai, em Brasília, no dia 23 de abril de 1969, promulgado pelo Decreto $N^{\circ}$ 67.084, de 19 de agosto de 1970.

O referido Decreto estabeleceu a parceria de uso das águas e dos recursos naturais, através de estudos mútuos, sem prejudicar os países à jusante do recurso hídrico. O documento estabeleceu que Brasil e Paraguai não poderiam construir usinas que criassem dificuldades ao uso posterior do rio. Assim, cada Estado seria soberano para realizar obras em seu território, desde que não prejudicasse outro país e fosse realizada a prévia comunicação de possíveis construções.

Conforme Raffestin (1993), na fronteira atuam diferentes agentes de poder, paralelos ao poder central do Estado, no entanto, para que ocorra a integração, fazse necessária a ação do Estado na dominação sobre a população e acerca dos recursos do território, atuando para mediar e negociar as tratativas que favorecem a soberania nacional, como evidenciaram os tratados e negociações com o Paraguai e a Argentina, feitos pelo Estado brasileiro.

Nesse sentindo, "o território é um trunfo particular, recurso e entrave, continente e conteúdo, tudo ao mesmo tempo. O território é o espaço político por excelência, o campo de ação dos trunfos." (RAFFESTIN, 1993, p. 59-60), por isso, denota atuação do poder. A área escolhida para a construção da Usina de Itaipu encontrava-se envolvida em disputas, contudo, o Estado brasileiro atuou de forma a preservar a autonomia e os interesses do País diante do Paraguai, apesar de algumas concessões no processo de negociação.

Em 1971, um consórcio internacional iniciou os estudos de topografia e batimetria com o intuito de indicar o melhor local para a construção da hidrelétrica, analisando diversos pontos do rio Paraná, desde o trecho do rio Iguaçu até a cidade de Guaíra. Dentre os vários pontos analisados, dois se destacaram: a ilha de Itaipu e a localidade de Santa Maria. Em razão das condições topográficas e geológicas, foi escolhida a ilha de Itaipu, onde o desvio e o fechamento do rio Paraná seriam mais convenientes (ITAIPU BINACIONAL, 2017).

Após diversas reuniões e acordos, em 1973, o presidente brasileiro, General Emílio Garrastazu Médici, e o presidente paraguaio, General Alfredo Stroessner, assinaram o Tratado de Itaipu, que criava oficialmente a entidade binacional, com a finalidade de aproveitamento dos recursos hídricos do Rio Paraná, constituída pela Central Elétrica Brasileira S.A. (ELETROBRÁS), do Brasil, e a Administración Nacional de Eletricidad (ANDE), do Paraguai. Conforme esse Tratado, a empresa 
pública, de constituição jurídica binacional, tem suas sedes em Brasília e Asunción, sendo regida pelo Anexo $A$, que contempla o estatuto da entidade; o Anexo $B$, o qual aborda a descrição das instalações e produção de energia; e o Anexo C, que regulamenta as bases financeiras e de prestação de serviços de eletricidade.

As bases financeiras constam no Anexo C, o qual aborda os custos dos serviços de eletricidade, participação de capital integrado anual, pagamento de encargos financeiros de empréstimos recebidos, montante necessário para o pagamento de empréstimos recebidos, pagamento de royalties mensais às partes contratantes, no caso o governo paraguaio e o brasileiro, ressarcimento de encargos administrativos à Eletrobrás e à Ande, além das despesas de exploração. Este Anexo foi aprovado em 1973, quando da assinatura do Tratado de Itaipu, com data prevista para revisão em 50 anos, o que acontecerá 2023 (BRASIL, TRATADO DE ITAIPU, 1973).

Essa revisão do Anexo C, prevista para 2023, aumentou a especulação a respeito da continuidade e do percentual de repasse dos valores dos royalties, recurso pago aos governos brasileiro e paraguaio pela Usina de Itaipu e redistribuído para os estados e municípios afetados pela formação do reservatório ou fornecedores dos recursos hídricos, bem como para órgãos federais brasileiros, como o Ministério do Meio Ambiente, o Ministério de Minas e Energia e o Fundo Nacional de Desenvolvimento Científico e Tecnológico.

Definido o local e oficializada a parceria entre os países, iniciou-se a fase de aquisição dos empréstimos para o início das obras. De acordo com dados disponibilizados por Zero (2019), os investimentos diretos relacionados à obra física da usina chegaram a US\$12 bilhões. No entanto, com os custos financeiros, esse montante elevou-se a US\$17 bilhões e, posteriormente, foi necessário captar novos recursos no exterior para rolar a dívida. O que ocorreu foi que, durante o segundo choque do petróleo, no início da década de 1980, o Federal Reserve praticamente duplicou a taxa básica de juros dos EUA, levando a dívida de Itaipu a entrar em uma espiral crescente. O resultado direto desse contexto foi o seguinte:

Ao todo, captaram-se recursos na ordem de US\$ 27 bilhões, remunerados com juros fixos de $7,5 \%$ ao ano, mais um fator de ajuste calculado com base na média ponderada de dois indicadores que medem a inflação norteamericana. Isso fez com que a taxa anual efetiva incidente sobre a dívida beirasse os $14 \%$ [...] o que aumentou a dívida ainda mais. No total, já foram efetuados pagamentos da dívida que ascendem a quase US\$ 60 bilhões, mas o saldo devedor ainda é de US\$5,6 bilhões. (ZERO, 2019) 
Essa dívida restante, conforme projeção estabelecida pela Itaipu, deverá ser paga totalmente até 2023, quando os recursos gerados pela usina poderão ser inteiramente repassados às "Altas Partes Contratantes", os representantes dos Estados paraguaio e brasileiro.

O Estado brasileiro coloca-se como principal agente empreendedor e financiador de Itaipu (e, em razão de uma conjuntura específica já abordada anteriormente, integra o Estado paraguaio no processo), projetando a ampliação do setor energético brasileiro através de onerosos empréstimos junto ao capital especulativo internacional. Desta forma, o Estado atuou criando o ambiente para que empresas do ramo de energia, grandes construtoras e o capital financeiro expandissem e se beneficiassem através dos empréstimos e importações de produtos industrializados, para a construção da Usina de Itaipu. Foi uma obra vantajosa para o mercado, através da ampliação da possibilidade de produção por meio do acréscimo de potencial do setor energético. O setor de trabalho também passou por intensa mobilização, com a ampliação da demanda por trabalhadores para a construção, em sua grande maioria, sem especialização e com contratos temporários.

As bases territoriais, financeiras e políticas estavam fundamentadas para viabilizar a construção do maior empreendimento hidrelétrico já realizado no século XX, figurando como a maior produtora de energia no mundo. Em 2016, a produção chegou a 103.098.366 MWh, um recorde mundial (ITAIPU BINACIONAL, 2017), produção esta obtida pelas suas 20 turbinas em funcionamento. Vale ressaltar que, com o ciclo de expansão de produção, houve o aumento de 18 turbinas projetadas para 20, sendo as duas últimas instaladas em 2007.

Tão grande quanto sua produção de energia foram as divergências surgidas no processo de desapropriação das áreas de terras para a formação do reservatório de Itaipu, nos dois lados da fronteira.

A Itaipu representa um projeto arquitetônico com elevados financiamentos internos e externos, de grande abrangência territorial, afetando diretamente 16 municípios no lado brasileiro, localizados nos estados do Paraná e do Mato Grosso do Sul, além dos departamentos de Alto Paraná e Canindeyú, no lado paraguaio, que contabilizaram 11 municipalidades afetadas.

Por outro lado, a Usina de Itaipu representa a maior geradora de energia para ambos os países, relevante para o Brasil por representar aproximadamente $15 \%$ de 
toda energia consumida no país (ITAIPU BINACIONAL, 2017). Além disso, é elemento fundamental para o processo de crescimento econômico, bem como para a ampliação do setor produtivo e do consumo residencial.

Para o Paraguai, a geração de energia de Itaipu representa aproximadamente $86 \%$ de toda a energia produzida (ITAIPU BINACIONAL, 2017), sendo que $90 \%$ da energia proveniente da Usina de Itaipu a que o Paraguai tem direito é vendida ao Brasil, haja vista que possui outras usinas que suprem sua necessidade de fornecimento, como é o caso das usinas de Yacyretá e Acaray. Portanto, como ressalta Codas (2008), o Paraguai exporta e ganha dinheiro com a produção e a venda de energia, principalmente através de Itaipu, mas também de Yacyretá, usina construída em parceria com a Argentina, da qual o governo argentino compra o excedente de produção não usado pelo Paraguai.

\section{Relevância do repasse de royalties do setor elétrico para a economia paraguaia}

O setor elétrico consta entre as atividades econômicas mais importantes do Paraguai. Em seu estudo, Paredes (2016) avalia a energia elétrica como o produto de exportação mais importante para o Paraguai:

\footnotetext{
El impacto más evidente se produce en el Producto Interno Bruto, afectando positivamente su nível, aumentando-lo en un promedio de $13,3 \%$ en términos reales en la serie analizada. Esto es como decir que apareció en La economía paraguaya un sector económico que pasa a formar parte del PIB y cuyo peso relativo lo posiciona entre las actividades económicas más importantes del país. En este mismo sentido, analizado el Producto Interno Bruto desde la perspectiva del gasto, se concluye de manera contundente que el producto de exportación del Paraguay número uno en importancia en la serie analizada, es la energia eléctrica (PAREDES, 2015, p. 103).
}

O objetivo do governo paraguaio com a construção das usinas binacionais (Itaipu e Yaciretá) foi de agregar recursos externos, pois o país apresenta, ainda na atualidade, baixa demanda de energia. Além das usinas binacionais de Itaipu e Yacyretá, outra importante usina é a de Acaray. As três garantem a demanda e a oferta de energia para o Paraguai.

Com potência instalada de $14.000 \mathrm{MW}$, a Itaipu conta com 20 turbinas, sendo que a casa de máquinas está localizada em Foz do Iguaçu (ITAIPU BINACIONAL). A usina binacional de Yacyretá também explora as águas do rio Paraná, estabelecida a $70 \mathrm{~km}$ a oeste das cidades de Posadas (Argentina) e Encarnación 
(Paraguai). Situada à jusante da Usina de Itaipu, ela conta com potência instalada de 3.200MW (USINA DE YACYRETA).

A terceira usina em importância, a hidrelétrica de Acaray, situa-se próxima da cidade de Hernandarias, com 4 turbinas geradoras de energia, potência instalada de 200MW, mas apresenta-se bastante modesta comparada com as duas maiores (USINA DE ACARAY). As principais usinas seguem a lógica da política econômica paraguaia de produção de energia para exportação, tornando este setor estratégico em termos de aquisição de receitas externas para o país.

A exemplo dos municípios e estados brasileiros afetados por usinas hidrelétricas e fornecedores dos recursos hídricos, os municípios paraguaios também recebem compensação financeira pelas áreas alagadas para a formação do reservatório. O diferencial em relação à distribuição brasileira é que todos os municípios e departamentos paraguaios recebem os royalties da Usina de Itaipu, mesmo aqueles que não tiveram locais afetados.

Esta regulamentação é amparada na Lei no 1309/98, a qual rege a distribuição e o depósito de parte dos recursos dos royalties aos governos dos departamentos e municípios paraguaios. A lei normatiza a divisão dos recursos das usinas binacionais de Itaipu e de Yacyretá.

Para o prefeito da municipalidade de Salto del Guairá, localizada no departamento de Canindeyú, a divisão dos royalties vigente no Paraguai é injusta com as municipalidades com área alagada para a formação do reservatório.

Para mim os royalties são uma injustiça, é uma injustiça. Primeiro porque também recebem royalties os municípios que estão a $600 \mathrm{~km}$ da área de influência da Itaipu Binacional, e ainda mais, essa distribuição é conforme a densidade populacional. Quando se firmou isso a população de Salto Del Guairá era de 10 mil habitantes, atualmente está entre 35 a 40 mil habitantes, e nós estamos recebendo 950 mil dólares anuais de royalties, varia de acordo com a produção de energia. Outros municípios que estão a uma distância de aproximadamente 600 a $700 \mathrm{~km}$ recebem muito mais, por causa da população. Primeira injustiça que estão recebendo também municípios que não tem nada que ver, que não foram afetados, isso ocorreu por uma decisão do parlamento, parlamento onde um deputado disse vamos conceder aos municípios afetados, porém com a condição de todos os municípios receberem (Carlos Cesar Haitter Cabrera, entrevista, 2018)5.

Ao total, são 17 departamentos paraguaios mais o distrito federal que recebem os recursos. Destes, somente cinco departamentos foram diretamente atingidos pelas usinas de Itaipu e Yacyretá e arrecadam 5\% dos royalties, mesmo

\footnotetext{
${ }^{5}$ Entrevista concedida por Carlos Cesar Haitter Cabrera (Intendente Municipal de Salto del Guairá período 2015-2020), Salto del Guairá - Paraguai, 30/01/2018. Tradução livre feita pela entrevistadora.
} 
percentual embolsado pelos outros 12 departamentos que não foram afetados pela formação dos reservatórios ou construção das usinas. Os departamentos diretamente afetados pela Usina de Itaipu foram Alto Paraná e Canindeyú, enquanto que a Usina de Yacyretá alagou terras nos departamentos de Itapúa, Misiones y Ñeembucú (Figura 1).

Figura 1 - Distribuição dos Departamentos paraguaios e localização do reservatório formado pela U.H. Binacional de Itaipu

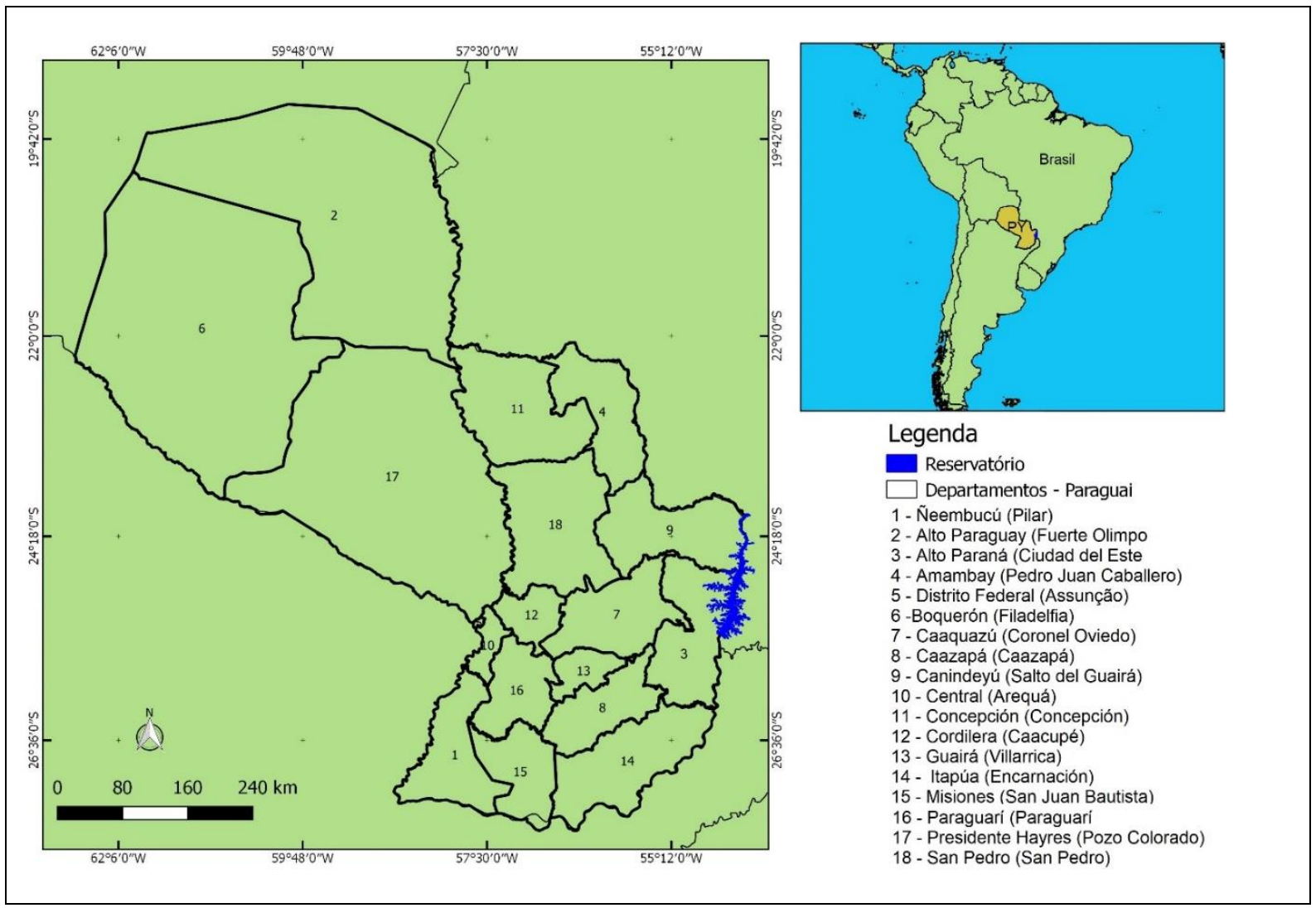

Elaborado por Bruno Aparecido da Silva (2019)

Em seu artigo 1ํㅜㄹ a Lei ํo 1309/98, que regulamenta a distribuição dos royalties, estabelece o seguinte:

Artículo $1^{\circ}$.- El ingreso total de los montos que provengan de los denominados "royalties" y de las "compensaciones en razón del territorio inundado" de las represas hidroeléctricas de Itaipú y Yacyretá, respectivamente, será distribuido de la siguiente manera:

a) a la administración central: el 50\% (cincuenta por ciento);

b) a las gobernaciones afectadas: el $5 \%$ (cinco por ciento); 
c) a las gobernaciones no afectadas: el 5\% (cinco por ciento);

d) a los municipios afectados: el 15\% (quince por ciento); $\mathrm{y}$,

e) a los municipios no afectados: el $25 \%$ (veinticinco por ciento). (PARAGUAI, 1998)

A responsabilidade pela distribuição e pelo depósito aos departamentos e municípios é do Ministério da Fazenda, em coordenação com os demais organismos técnicos do Estado, tendo o prazo de 15 dias logo após o depósito na Administração Central para realizar o repasse.

A distribuição foi implementada de forma gradativa a partir do ano 2000 (Gráfico 1), iniciando com um percentual mínimo de 10\%. A partir do segundo ano, proporção mínima de 5\%, até completar os percentuais estabelecidos no artigo 1ำ da Lei 1309/98 (PARAGUAI,1998).

Gráfico 1 - Organograma da distribuição atual dos royalties das U.H. de Itaipu e Yacyretá no Paraguai

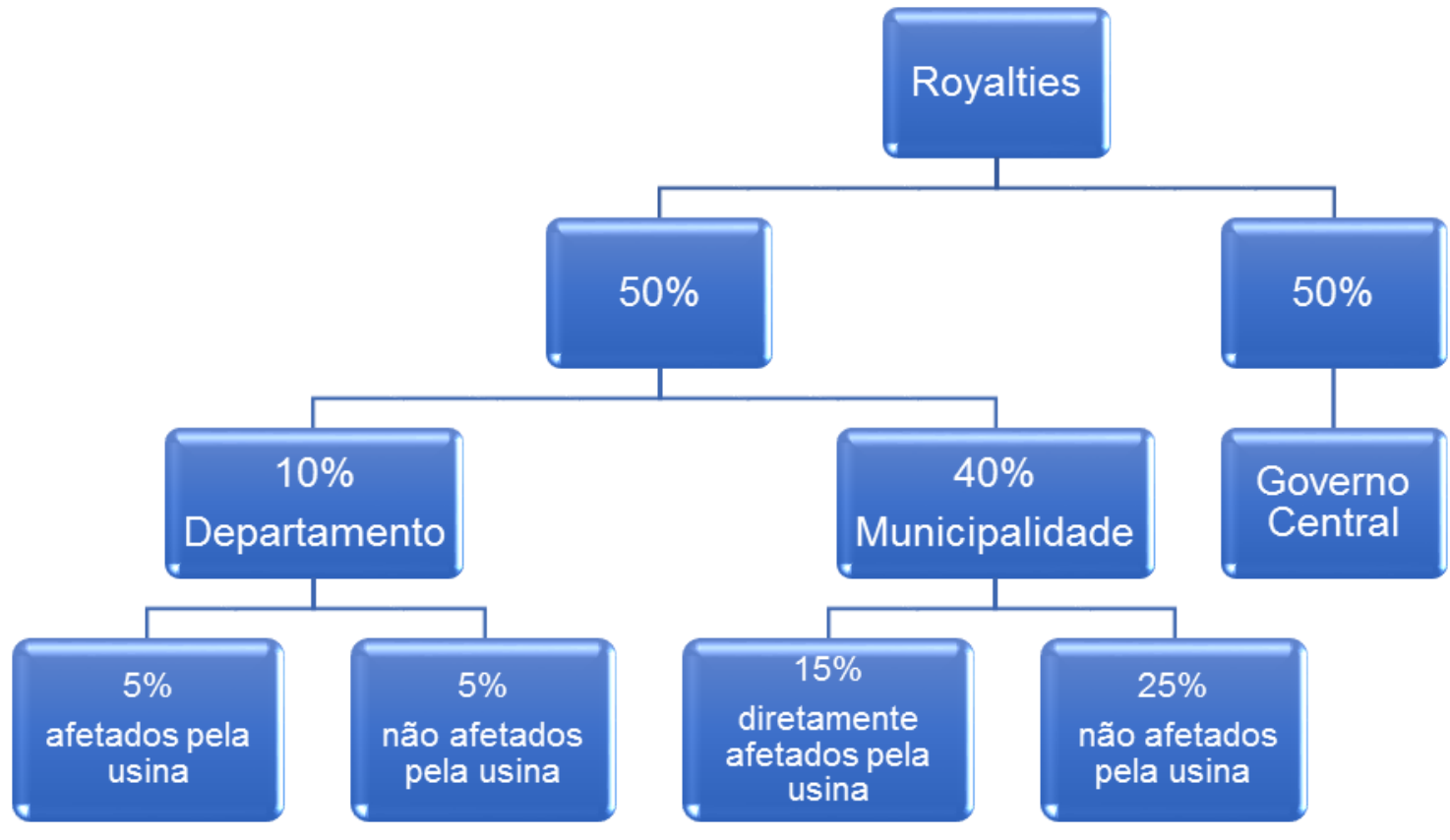

Fonte: Lei no 1309/98 (PARAGUAI, 1998)

Entre 1985 e 1999, esses recursos eram administrados pelo governo central paraguaio, distribuídos entre as agências e os organismos dessa administração, sem critérios prévios. Em seu estudo, Gavilán (2010) analisa a aplicação dos recursos recebidos entre os anos de 1992 a 2009 e classifica a aplicação como ineficiente por falta de um planejamento estratégico, com relativa melhora a partir da 
aprovação da Lei 1309/98. Porém, mesmo com essa melhora, o autor ressalta a falta de responsabilidade das administrações públicas.

Esta afirmación se basa en las respuestas de 10 especialistas entrevistados, que también coinciden en que las gobernaciones y municipalidades, aun que no todas, la gran mayoría han mal utilizado los recursos (royalties y compensaciones) distribuidos a estas administraciones. Aclaran que tantos los municipios como las gobernaciones, han crecido enormemente en sus presupuesto gracias a estos recursos, pero sin embargo el aspecto físico de las ciudades que administran no han cambiado mucho teniendo en cuenta los años que ya han venido recibiendo (GAVILÁN, 2010, p. 07).

Nesse sentido, Gavilán (2010) destaca o aumento considerável do orçamento dos municípios em decorrência do repasse dos royalties e das compensações. Em contrapartida, avalia que a aplicação desses recursos não promoveu um desenvolvimento significativo junto às cidades beneficiadas.

No conjunto dos municípios paraguaios, 52 são recebedores do percentual de $15 \%$ dos recursos por terem sido afetados diretamente pela formação da barragem das usinas de Itaipu e Yacyretá, enquanto que outros 202 municípios, que não tiveram área alagada pela implantação dessas duas usinas, dividem entre si o percentual de 25\% (Lei 3512/2008) (PARAGUAI, 2008).

No que concerne à aplicação desses recursos, esta foi normatizada pela Lei nำ2979/06, que estabelece no artigo 1을

obligatoriamente deberán ser destinados en un mínimo de 85\% (ochenta y cinco por ciento) en gastos de capital y aplicados en las áreas de desarrollo urbano, infraestructura vial, educación, salud, desarrollo productivo y medio ambiente. El 15\% (quince por ciento) restante podrá ser utilizado para el financiamiento de proyectos de inversión, de fiscalización de obras o de gastos corrientes vinculados a los gastos de capital. (PARAGUAI, 2006)

O artigo $2^{\circ}$ da mesma Lei enfatiza que os recursos para o desenvolvimento produtivo devem fomentar a agricultura mini fundiária, com fortalecimento das pequenas empresas e capacitação das famílias de baixa renda, determinando que a aplicação por parte dos departamentos e municípios não deverá ser inferior a 20\% do valor nesta área econômica (Lei 2.979/06) (PARAGUAI, 2006).

Referindo-se à lei que estabelece a aplicação dos royalties, o prefeito de Salto del Guairá avalia as restrições na aplicação dos recursos e a articulação política para ampliar as possibilidades de seu uso em outros setores municipais.

Sim tem uma lei que condiciona a aplicação deles [dos royalties], inclusive somente para infraestrutura e desenvolvimento, nós estamos discutindo a nível de município com as organizações sociais referente a possibilidade de ampliar a abertura dessa lei, que nos permita comprar lotes para doar para 
a população que não tem teto, mas a lei nos proíbe (Carlos Cesar Haitter Cabrera, entrevista, 2018).

Assim como ocorre no território brasileiro, o repasse dos royalties é importante fonte de fomento econômico no território paraguaio. A tabela 1 apresenta o acumulado dos valores pagos em dólar para o governo do Paraguai pela Usina de Itaipu, desde 1989 até março de 2019. Em proporção, o ano de 1998 apresenta o maior valor de repasse, por conta do recorde da produção de energia naquele ano.

Até dezembro de 2018, a Usina de Itaipu contabilizava o repasse de mais de US\$ 11 bilhões para os governos do Brasil e do Paraguai - metade para cada país (ITAIPU BINACIONAL, 2019). O recurso, já previsto no Tratado de Itaipu, assinado em 1973, começou a ser pago com o início da comercialização de energia gerada pela usina, em março de 1985. Porém, anteriormente à Lei 1309/98 no Paraguai e ao Decreto $\mathrm{n}^{0}$ 1, de 11 de janeiro de 1991, esses dividendos eram repassados somente aos governos centrais, tanto no Brasil quanto no Paraguai.

Tabela 1 - Repasse de royalties ao Estado paraguaio no período de 1989 a 2020* (em milhões de US\$)

\begin{tabular}{|llll}
\hline ANO & TOTAL U\$ & ANO & TOTAL U\$ \\
\hline $\mathbf{1 9 8 9}$ & $36.734,56$ & $\mathbf{2 0 0 5}$ & $183.066,88$ \\
$\mathbf{1 9 9 0}$ & $80.245,80$ & $\mathbf{2 0 0 6}$ & $196.516,00$ \\
$\mathbf{1 9 9 1}$ & $77.925,10$ & $\mathbf{2 0 0 7}$ & $206.723,00$ \\
$\mathbf{1 9 9 2}$ & $123.886,09$ & $\mathbf{2 0 0 8}$ & $218.892,10$ \\
$\mathbf{1 9 9 3}$ & $123.787,99$ & $\mathbf{2 0 0 9}$ & $231.589,10$ \\
\hline $\mathbf{1 9 9 4}$ & $160.303,31$ & $\mathbf{2 0 1 0}$ & $211.914,58$ \\
\hline $\mathbf{1 9 9 5}$ & $123.154,74$ & $\mathbf{2 0 1 1}$ & $222.844,20$ \\
$\mathbf{1 9 9 6}$ & $104.214,40$ & $\mathbf{2 0 1 2}$ & $246.706,91$ \\
$\mathbf{1 9 9 7}$ & $163.965,27$ & $\mathbf{2 0 1 3}$ & $258.912,90$ \\
\hline $\mathbf{1 9 9 8}$ & $294.175,64$ & $\mathbf{2 0 1 4}$ & $273.191,60$ \\
\hline $\mathbf{1 9 9 9}$ & $155.382,56$ & $\mathbf{2 0 1 5}$ & $250.511,50$ \\
\hline $\mathbf{2 0 0 0}$ & $147.100,46$ & $\mathbf{2 0 1 6}$ & $240.012,70$ \\
\hline $\mathbf{2 0 0 1}$ & $244.869,90$ & $\mathbf{2 0 1 7}$ & $257.952,30$ \\
\hline $\mathbf{2 0 0 2}$ & $143.062,80$ & $\mathbf{2 0 1 8}$ & $238.144,80$ \\
\hline $\mathbf{2 0 0 3}$ & $153.806,20$ & $\mathbf{2 0 1 9}$ & $246.706,91$ \\
\hline
\end{tabular}


2004

$166.514,56$

2020*

$41.584,87$

\section{TOTAL GERAL $\quad 5.824 .399,73^{\star}$}

Fonte: ITAIPU BINACIONAL (2020). *Repasse computado até o dia 31/03/2020.

Os royalties pagos pelas usinas hidrelétricas são importantes fontes de captação e repasse de recursos aos municípios. Segundo o Ministério da Fazenda do governo paraguaio, no primeiro semestre de 2018, o maior montante de repasse para os municípios foi proveniente dos royalties, totalizando um valor (em guaranis) de $G \$ 359.448$ milhões, seguido por G\$153.713 milhões provenientes do Fonacide ${ }^{6}$, G\$13.963 milhões advindos de jogos de azar, além de demais recursos totalizarem G\$ 33.489 de milhões.

Para ilustrar a representação desses recursos, apresentamos o fechamento do ano de 2017, quando o repasse de recursos do Ministério da Fazenda aos municípios totalizou o valor de $\mathrm{G} \$ 1.349 .664$ bilhão, dos quais $\mathrm{G} \$ 775.212$ milhões foram provenientes dos royalties, o que perfaz um percentual de $57 \%$, das transferências financeiras para os municípios paraguaios, conforme indicado no gráfico abaixo (MINISTÉRIO DA FAZENDA).

É representativo o percentual de repasse dos royalties aos municípios e a importância da energia das Usinas de Itaipu e Yacyretá para o Paraguai. Rolon (2010) destaca que o aproveitamento hídrico, através da construção de barragens, é uma forma de capitalizar o país por meio da venda do excedente para o Brasil e para a Argentina.

Gráfico 2 - Transferências financeiras para os municípios paraguaios entre janeiro e dezembro de 2017

\footnotetext{
${ }^{6}$ Algumas informações adicionais sobre esse Fundo serão acrescentadas mais à frente.
} 


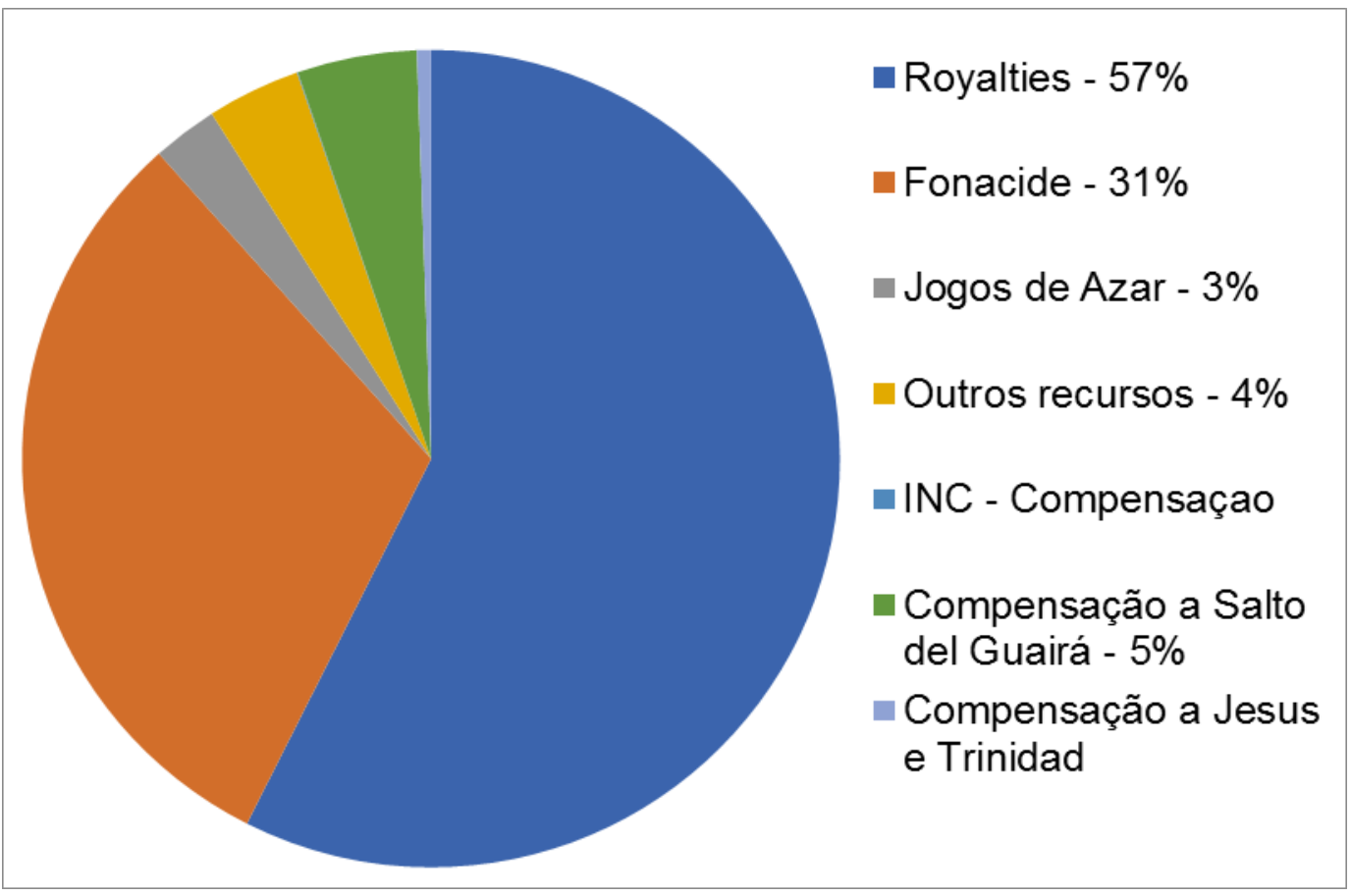

Fonte: Ministério da Fazenda (PARAGUAI, 2018).

Nesse sentido, reafirma-se a importância desse recurso ao analisarmos as características do Paraguai: país pouco populoso, com baixa demanda de energia, características geográficas desfavoráveis em algumas áreas, como a presença de região árida - o chaco, limitação de acesso ao mar por terra, com possibilidade de fazê-lo através da Bacia do Prata.

Outro fator a enaltecer é a sua localização no coração da América do Sul, situada entre as duas principais potências sul-americanas. A geopolítica paraguaia atuou para manter a soberania nacional e o estreitamento das relações políticas comerciais entre os países vizinhos. "Itaipu talvez seja um exemplo típico da estreita relação política e econômica, que envolve interesses econômicos e políticos de natureza interna e externa, atendendo aos propósitos e aos interesses dos governos dos países." (ROLON, 2010, p. 94).

Os benefícios deste grande empreendimento para o Brasil, representado pela construção da U.H. Binacional de Itaipu, revelam-se para além da produção de energia. Significou, também, a possibilidade de ocupação de uma área de fronteira que estava em litígio com o Paraguai, conforme abordado anteriormente, assim como motivou a política externa de aproximação com o Paraguai, pois tanto o Brasil quanto a Argentina estabeleciam relações e disputavam a influência no continente sul americano, bem como a viabilidade de conseguir energia com menor custo. Nesse sentido, o valor pago pelo Brasil ao excedente de energia vendido pelo 
Paraguai sempre esteve envolto em polêmicas e sofreu alguma modificação com a renegociação, a qual alterou as bases financeiras do Tratado de Itaipu em 2009, discussão esta que abordaremos oportunamente.

A construção da Usina de Itaipu foi norteada por tratados e acordos em comum, porém, a destinação e a aplicação interna dos royalties e compensações seguem as leis de cada país. No Paraguai, como destacado anteriormente, a Lei no 1309/98 regulamenta a distribuição dos royalties aos departamentos e municípios, tendo sido a aplicação desses recursos normatizada pela Lei 2979/06 e pelas Leis $1829 / 01,2391 / 04,2442 / 04,2824 / 05$, as quais foram atualizadas pela Lei 3512/08, que nomeia os departamentos e municípios com direito a receber os royalties das usinas de Itaipu e Yacyretá.

Os departamentos de Alto Paraná e Canindeyú foram diretamente afetados pela formação do reservatório de Itaipu, dividindo entre si de forma igualitária o percentual de $5 \%$ de royalties repassados mensalmente pela Usina de Itaipu.

No departamento de Alto Paraná os municípios de Hernandarias, Minga Porá, Mbaracayú, San Alberto, Itakyry e Santa Fe del Paraná tiveram áreas alagadas pelo reservatório da usina de Itaipu. No departamento de Canindeyú, recebem os recursos, por conta da mesma situação, os municípios de Salto del Guairá, Corpus Christi, General Francisco Caballero Alvarez, La Paloma, Katueté, Nueva Esperanza e Puerto Adela (figura 3). Esses municípios dividem entre si o valor de $15 \%$ dos royalties repassados pela Usina de Itaipu ao Ministério da Fazenda, sendo a divisão proporcional à quantidade de população existente em cada município.

Figura 3 - Departamentos de Alto Paraná e Canindeyú e respectivos municípios 


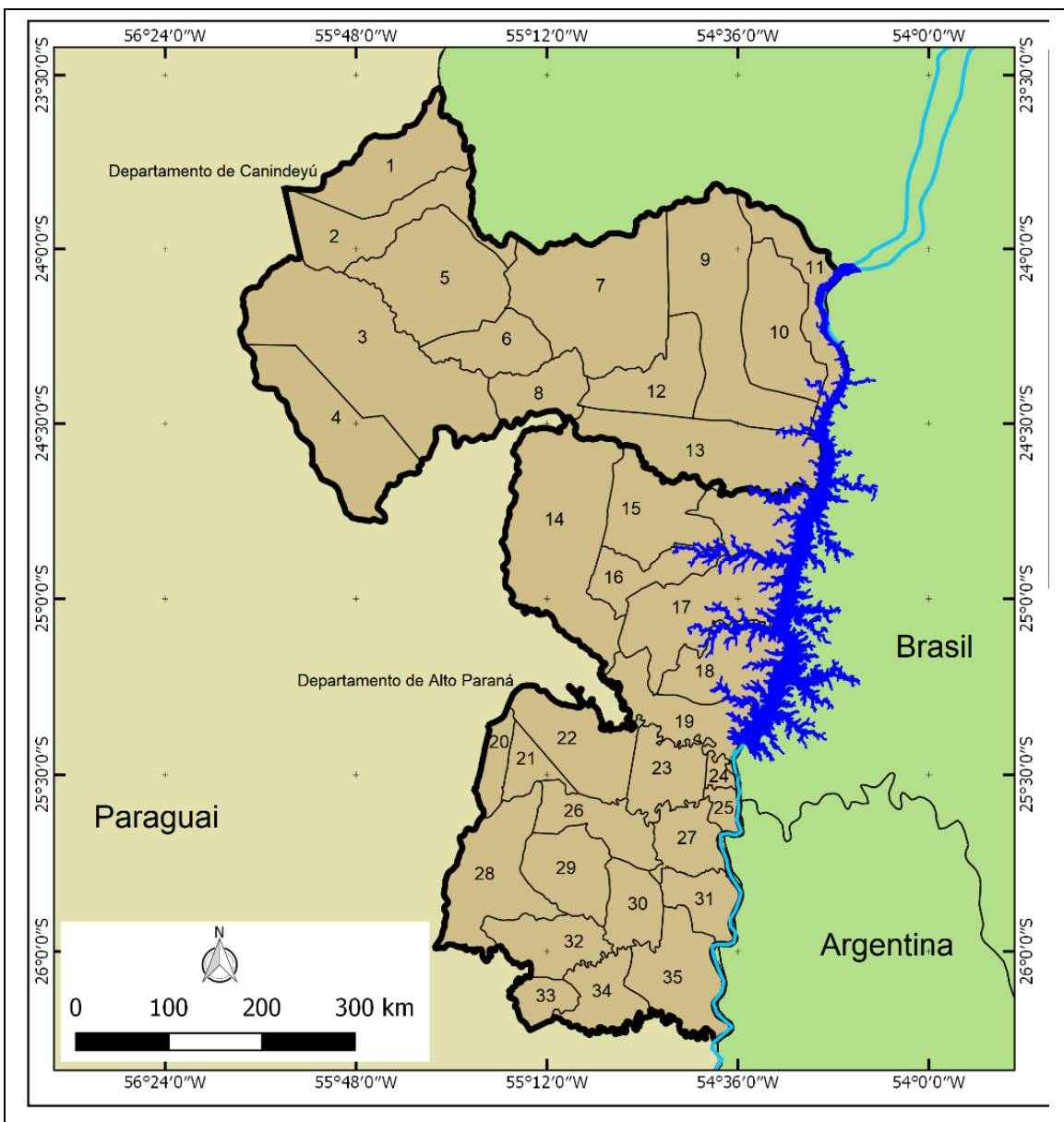

\begin{tabular}{|l|l|}
\hline & Reservatório de Itaipu \\
\hline Municípios \\
\hline 7 & Corpus Christi \\
\hline 10 & General Francisco C. Alvarez \\
\hline 1 & Itanara \\
\hline 11 & Salto del Guairá \\
\hline 3 & Villa San Isidro Curuguaty \\
\hline 5 & Villa Ygatimí \\
\hline 2 & Ypejhuí \\
\hline 24 & Ciudad del Este \\
\hline 21 & Doctor Juan León Mallorquín \\
\hline 31 & Domingo Martínez de Irala \\
\hline 19 & Hernandarias \\
\hline 4 & Yasy Kañy \\
\hline \hline 6 & Yby Pytá \\
\hline \hline 8 & Ybyraroboná \\
\hline 12 & Katuete \\
\hline 13 & Nueva Esperanza \\
\hline 33 & D. Raul Peña \\
\hline 14 & Itakyry \\
\hline 20 & Juan Emilio O'Leary \\
\hline 27 & Los Cedrales \\
\hline 17 & Mbaracayú \\
\hline 23 & Minga Guazú \\
\hline 15 & Minga Porá \\
\hline 35 & Ñacunday \\
\hline 32 & Naranjal \\
\hline 25 & Presidente Franco \\
\hline 16 & San Alberto \\
\hline 28 & San Cristóbal \\
\hline 29 & Santa Rita \\
\hline 30 & Santa Rosa del Monday \\
\hline 22 & Yguazú \\
\hline 18 & Sta Fé del Paraná \\
\hline 26 & Tevapy \\
\hline 334 & Nuña \\
\hline
\end{tabular}

Elaborado por Bruno Aparecido da Silva (2019)

Outra particularidade é a lei que foi aprovada no ano de 2015, Lei no 5404/15, de compensação aos municípios do departamento de Canindeyú, pelo desaparecimento dos Saltos del Guairá. A referida lei de compensação pela perda dos saltos das Sete Quedas, em decorrência da formação do reservatório da Usina de Itaipu, estabeleceu em seu artigo $2^{\circ}$ que a retribuição monetária será paga pelo Estado paraguaio a todos os municípios do departamento de Canindeyú. O pagamento será efetuado pelo Ministério da Fazenda, de modo que 2,33\% serão destinados ao município de Salto del Guairá, e os demais municípios do departamento dividirão o equivalente a 0,67\%, distribuídos em partes iguais, calculado sobre a totalidade dos recursos provenientes da Nota Reversal n 4/09, aprovada pela Lei no 3923/09.

A Nota Reversal ${ }^{7}$ no 4/09 refere-se à revisão do Artigo XV do Tratado de Itaipu, estabelecido entre os governos brasileiro e paraguaio no ano de 2009 , nos

\footnotetext{
7 O conceito jurídico de carta ou nota reversal, utilizada em relações diplomáticas entre dois países, refere-se ao instrumento formal pelo qual um país faz uma concessão em troca de outra do segundo país. Fonte: < https://pt.scribd.com/document/355942891/Notas-Reversais-Exelencia-Energetica>
} 
mandatos de Luiz Inácio Lula da Silva (2003-2010) e Fernando Lugo de Méndez (2008-2012). Naquele momento, os governantes, em consenso, alteraram o valor pago pela energia cedida pelo Paraguai ao Brasil.

Com a alteração efetuada pelos governos em 2009, através da Nota Reversal no 4/09 da Lei 3923/09, o valor que passou a vigorar foi multiplicado por 15,3 a quantidade necessária para a compensação das altas Partes Contratantes gigawatthora cedido à outra Parte Contratante. O fator multiplicador anterior era de 5,1, acordados por notas reversais entre os países no ano de 2005, entrando em vigor em janeiro de 2006 (ITAIPU BINACIONAL, 2017).

O incremento de recursos provenientes desse acordo (que não deve ser confundido como o repasse dos royalties), permitiu ao Estado paraguaio aprovar, pela Lei no 4.578/12, o FONACIDE (Fondo Nacional de Inversión Pública y Desarrollo), que segundo Sentrini \& Recalde (2019, p. 79),

[...] creó [para as administrações municipais] un flujo inesperado de recursos destinados a la infraestructura local y otros gastos que en teoría podrían usarse para sustituir gastos del gobierno central, pero no estableció procedimientos de auditoría o control administrativo para el uso de estos fondos.

Também é indispensável a menção à Lei no 5.404/15, que passou a vigorar a partir de 23 de abril de 2015 e beneficiou exclusivamente os municípios afetados pela formação do reservatório da usina de Itaipu. Esta Lei estabelece que os recursos provenientes do ressarcimento deveriam ser aplicados exclusivamente para a construção de obras de infraestrutura em turismo, planejamento urbano, estradas, esgotos, pavimentação, manutenção de ruas, saúde e educação. Os governos municipais e distritais do departamento de Canindeyú deveriam elaborar um plano anual para o investimento do valor transferido como compensação (Lei no 5.404/15).

Anteriormente a esta lei de compensação financeira aos governos municipais do departamento de Canindeyú, havia a Lei nำ 4.597/12, que regulamentava a compensação somente ao município de Salto Del Guairá pela perda dos saltos. Porém, devido às intervenções e aos interesses dos representantes políticos dos demais municípios do departamento, houve a alteração da Lei, conforme relata o prefeito do município de Salto Del Guairá.

Tem uma lei agora de 2015, se chama lei de ressarcimento pela perda dos Saltos de Guairá, é uma lei especial para Salto Del Guairá. [...] foi uma 
decisão do parlamento [nacional] de dar a Salto del Guairá uma porcentagem, e que essa porcentagem alcançará 10 milhões de dólares anuais, que foi diminuindo porque foi criado outro município [emancipado de Salto del Guairá]. Atualmente Salto Del Guairá recebe oito milhões 600 mil dólares anuais pela lei de ressarcimento. Era para ser só Salto, mas como começou a separar, outros municípios também recebem ressarcimento pela perda dos saltos das Sete Quedas. (Carlos Cesar Haitter Cabrera, entrevista, 2018).

$\mathrm{Na}$ análise do gestor do município de Salto Del Guairá, o Estado paraguaio e a Usina de Itaipu têm uma dívida muito grande com este município. Cabrera (2018), salienta que o repasse da compensação ao município de Salto del Guairá é irrisória frente à perda das "Sete Quedas", que representava um potencial turístico importante para o município.

Com a ampliação do repasse dos recursos através da Lei ํㅜ 5404/15, o município de Salto Del Guairá está construindo uma avenida costaneira e uma praia às margens do reservatório, um complexo turístico com valor estimado de US\$12 milhões, financiados através da compensação recebida pela perda dos saltos - os primeiros 300 metros da praia foram inaugurados em dezembro de 2018. O gestor municipal demonstra sua insatisfação diante da inexpressiva atuação da empresa de Itaipu no território paraguaio.

[...] recentemente os prefeitos de Salto del Guairá anteriores começaram a reivindicar e nós conseguimos que a Itaipu conceda em usufruto uma área de 42,6 hectares, aproximadamente 20 alqueires para o desenvolvimento do projeto da Avenida Costa Negra e Praia, mas quem financiou isso é o dinheiro da lei de ressarcimento (Carlos Cesar Haitter Cabrera, entrevista, 2018).

A construção compreende uma avenida dupla de 3.500 metros, ciclovia de aproximadamente 2.000 metros e uma segunda ponte sobre o rio Piratiy, a obra será em uma área cedida em comodato pela Itaipu Binacional (ITAIPU BINACIONAL).

De acordo com o apresentado, é possível perceber que uma característica marcante nas relações entre o governo central e as administrações municipais é a assimetria e a alta dependência dessas últimas ao primeiro quanto à transferência de recursos financeiros. Para Sentrini \& Recalde (2019), esse é um problema generalizado no Paraguai, com algumas poucas exceções como Asunción e outros grandes centros urbanos que possuem uma base de receita proveniente de impostos cobrados pela propriedade urbana e tarifas de serviço ambiental.

\section{Considerações Finais}


A construção de usinas hidrelétricas de grande porte provoca vários impactos de ordem econômica, social, ambiental e, por consequência, de rearranjo territorial sobre extensa área e, frequentemente, sobre grande número de pessoas atingidas. O Estado e as empresas públicas ou privadas responsáveis por esse tipo de empreendimento alegam que as externalidades negativas seriam compensadas através do repasse dos royalties e/ou de outros tipos de compensação, que promoveriam o desenvolvimento regional.

No entanto, a garantia do recebimento destes recursos, que representam valores significativos dos orçamentos municipais paraguaios, não se reverte automaticamente no desenvolvimento econômico/regional e, menos ainda, em ganho social para os habitantes dos municípios. Para atingir algo próximo desse tipo de objetivo, seriam necessários, no mínimo, planejamento de longo prazo, fiscalização por parte da sociedade sobre a destinação desses recursos, além de envolvimento de forma diversificada e horizontal da população através da gestão democrática, com ampla informação sobre os valores e abertura para a sugestão de aplicações condizentes e em benefício do conjunto da população. Contudo, a grande questão que se coloca é, tanto do lado brasileiro quanto do paraguaio: as condições sociais e institucionais para essa gestão democrática estão dadas para funcionar de forma eficiente e concreta?

Ao mesmo tempo em que passa a ideia de soberania nacional e bem-estar social, o Estado atua privilegiando grupos e corporações que possuem maior influência sobre si. Essas práticas se manifestam, mais ou menos intensamente, conforme o grau de organização das instituições públicas e dos mecanismos de controle social, viabilizados pelo nível de transparência do setor público.

Há diferenças evidentes entre os Estados compostos em sociedades de democracia consolidada e aqueles que possuem atuação repressora e com menor abertura às críticas e à fiscalização. No entanto, de forma estruturante e geral, as prerrogativas de escolha do Estado, ainda mais em tempos recentes de hegemonia neoliberal, perpassam predominantemente pela atuação do capital e sua reprodução. Sob esse referencial, apresenta-se o exemplo dos rendimentos provenientes das usinas hidrelétricas de Itaipu e de Yacyretá, que são analisados como exponenciais recursos para o aumento do PIB paraguaio, dentro de uma perspectiva mais voltada para a busca do crescimento econômico do que para o desenvolvimento social - em sentido amplo. 
Conforme as normatizações apresentadas, relativas ao repasse dos royalties da Itaipu aos municípios paraguaios, desperta a atenção duas questões: a centralização dos recursos por parte de Asunción (enquanto sede do governo nacional) e o repasse desproporcional aos municípios que tiveram áreas diretamente atingidas pela formação do reservatório, que, na avaliação de seus representantes políticos, não recebem a justa compensação, apesar de terem obtido avanços em algumas de suas reivindicações mais recentemente.

O formato de concepção e de formação da empresa Itaipu Binacional, pertencente a dois países e com dois sócios - Eletrobrás e Ande, extrapolou a jurisdição nacional vigente dos dois países. Em decorrência desse fator, ampara-se no direito internacional e, desse modo, qualquer medida relativa à empresa deve ter aprovação e autorização prévia de maneira binacional. No entanto, a normatização relacionada ao repasse dos royalties aos entes federativos apresenta-se diferenciada para cada país, de acordo com as especificidades e o nível de articulação política (disputas de poder) de grupos que conseguiram encaminhar suas demandas junto ao Estado, viabilizadas pelas decisões aprovadas nos seus respectivos legislativos.

\section{REFERÊNCIAS}

BARROS, Luiz E.P. Os saltos da discórdia: o impasse entre Brasil e Paraguai em torno das Sete Quedas (1962-1966). Dissertação (Mestrado em História, Região e Identidades) Universidade Federal da Grande Dourados (UFGD), Dourados (MS), 2012. Disponível em: $<$ https://www.ppghufgd.com/wp-content/uploads/2017/06/LUIZ-EDUARDO-PINTOBARROS.pdf $>$

BRASIL. Decreto no 4.911, de 27 de março de 1872. Promulga o tratado de limites entre o Império do Brasil e a República do Paraguay. Disponível em: https://www2.camara.leg.br/legin/fed/decret/1824-1899/decreto-4911-27-marco-1872550978-publicacaooriginal-67047-pe.html

BRASIL. Ata de Iguaçu, de 22 de junho de 1966. Disponível em: $<$ http://jie.itaipu.gov.br/sites/default/files/u39/ataiguacu-1.pdf>

CASTRO, Iná Elias de. Geografia e Política: território, escalas de ação e instituições. Rio de Janeiro: Bertrand Brasil, 2005.

CODAS, Gustavo (Org.). 0 direito do Paraguai à soberania. São Paulo: Editora Expressão Popular, 2008. 
FERRAZ, Octavio Marcondes. Octavio Marcondes Ferraz: um pioneiro da engenharia nacional. Depoimento/Centro da Memória da Eletricidade no Brasil: coordenação Renato Feliciano Dias. Rio de Janeiro: Memória da Eletricidade, 1993.

GAVILÁN, Pablo Ramón Alcaraz. Royalties y compensaciones: influencia en la política socio-económica del estado paraguayo en el período 1992-2009. Assunción: Pilar, 2010.

ITAIPU BINACIONAL. Tratado de Itaipu (Brasília, 26.4.1973) Disponível em: $<$ https://www.itaipu.gov.br/sites/default/files/u13/tratadoitaipu.pdf $\geq$

ITAIPU BINACIONAL. Royalties. 2017. Disponível em: <http://www.itaipu.gov.br>

IWAKE, Shiguera. Análise das modificações na estrutura orçamentária dos municípios lindeiros recebedores de royalties de Itaipu. Diálogo Econômico. Paraná: CORECON, no 3, p. 24 - 25, fev. 2005.

JORNAL DO BRASIL - Rio de Janeiro, terça-feira dia 21 de janeiro de 1964. Disponível em: $<$ http://memoria.bn.br/pdf/030015/per030015 1964 00017.pdf >

LIMA, Ivone Teresinha Carletto. Itaipu: as faces de um mega projeto de desenvolvimento (1930 - 1984). Marechal Cândido Rondon: Germânica, 2006.

LORENZON, Alexandre Simões. Revisando a distribuição espacial dos royalties da usina hidrelétrica de Itaipu: a bacia hidrográfica como unidade de análise. 2016. 363f. Tese (Doutorado em Ciência Florestal) - Universidade Federal de Viçosa, Viçosa. 2016.

MARTINS, Vanderlei Affonso. COSTA, Isabella Vaz Leal da. SANTOS, Ana Cláudia Cirino dos. Nova conjuntura da compensação financeira de usinas hidrelétricas e dos royalties de Itaipu no Brasil. FGV Energia - Boletim energético; jun. 2018. Disponível em: https://fgvenergia.fgv.br/sites/fgvenergia.fgv.br/files/coluna opiniao junho- vanderleiisabella e ana claudia.pdf

OLIVEIRA, Leoveraldo Curtarelli de. Economia, instituições e royalties: o caso dos municípios lindeiros ao lago de Itaipu Binacional no oeste paranaense. 2008. Dissertação (Mestrado em Desenvolvimento Regional e Agronegócio) - Toledo, Universidade Estadual do Oeste do Paraná. Disponível em: <http://tede.unioeste.br/tede/tde arquivos/2/TDE-200807-17T132449Z-253/Publico/Leoveraldo\%20C \%20de\%20Oliveira.pdf>

PARAGUAI. Ley n 4.597 - especial de compensación al municipio de Salto del Guairá. Disponível em: <http://www.bacn.gov.py/leyes-paraguayas/1265/especial-de-compensacional-municipio-de-salto-del-guaira-por-la-desaparicion-de-los-saltos-del-guaira $>$

PARAGUAI. Ley no 1309/98. Disponível em: https://paraguay.justia.com/.../leyes/...ley-130998.../gdoc

PARAGUAI. Ley $\mathbf{n}^{\circ}$ 2.979/06. Disponível em: www.leyes.com.py/todas disposiciones/.../leyes/ley 2979 06.php

PARAGUAI. Ley № 5404 /15. De compensación a los municipios del departamento Canindeyú en reparación por la desaparición de los Saltos del Guairá, en el marco de la distribución de compensaciones de la entidad binacional Itaipú. Disponível em: www.bacn.gov.py/leyes.../de-compensacion-a-los-municipios-del...

PAREDES, Rodi H. O. Impacto generado en la economia paraguaya por la inclusión de las transacciones de las entidades binacionales Itaipú y Yacyretá en las cuentas 
nacionales y en la balanza de pagos - período 1994 al 2010. Tesis (Doctorado em Ciências Económicas) - Facultad de Ciências Económicas de la Universidad Nacional de Asunción, San Lorenzo, 2016. Disponível em:

$<$ https://www.eco.una.py/eco/postgrado/tesis/2016/TESIS DOCTORADO RODI V Marzo\% 20 152016.pdf>

PEREIRA, Osny Duarte. Itaipu - prós e contras. Rio de Janeiro: Editora Paz e Terra, 1974.

RAFFESTIN, Claude. Por uma Geografia do Poder. São Paulo: Ática, 1993.

ROCHA, Renata Rodrigues de Castro. A revisão do tratado de Itaipu e a necessidade de um novo marco regulatório para a compensação financeira pelo uso dos recursos hídricos: um desafio para o Brasil de 2023. Tese (Doutorado em Ciência Florestal) - UFV, Viçosa (MG), 2012.

ROLON, José Aparecido. Paraguai: transição democrática e política externa. 2010. Tese (Doutorado em Ciência Política) - Faculdade de Filosofia, Letras e Ciências Humanas, USP, São Paulo, 2010. Disponível em: <https://teses.usp.br/teses/disponiveis/8/8131/tde30042010-114706/pt-br.php>

SENTRINI, Gustavo A.; RECALDE, Liliana R. D. El desarrollo de instituciones participativas em Paraguay: ¿una herramienta para la democratización o para el control estatal? Revista Paraguay desde la Ciencias Sociales, Instituto de Estudios de América Latina y el Caribe, Universida de Buenos Aires, no 10, p. 68-89, nov. 2019. Disponível em < https://publicaciones.sociales.uba.ar/index.php/revistaparaguay/article/view/4697>

SILVA, Suana Medeiros. Quando o galo insiste em cantar: Sobre o Estado moderno, a reprodução capitalista e a luta de classes. In: Anais do XI Encontro Nacional da ANPEGE, UNESP - P. Prudente, 09 a 12 out. 2015. Disponível em:

$<$ http://www.enanpege.ggf.br/2015/anais/arquivos/13/424.pdf>

THIBES, Juliana S. Itaipu - a pedra que canta e desencanta: uma análise dos royalties na educação nos municípios de Santa Helena e Itaipulândia (2003 - 2016). Dissertação (Mestrado em Educação) - UNIOESTE - Campus de Cascavel, 2019.

ZERO, Marcelo. Para entender a crise de Itaipu. Blog Outras Palavras. 22 ago. 2019. Disponível em: https://outraspalavras.net/mercadovsdemocracia/para-entender-a-crise-deitaipu/

\section{NOTAS DE AUTOR}

\section{CONTRIBUIÇÃO DE AUTORIA}

Nilse Girotto - Concepção e elaboração do manuscrito. Coleta e análise de dados. Revisão e aprovação da versão final do trabalho

Edson dos Santos Dias - Concepção e elaboração do manuscrito. Participação ativa da discussão dos resultados. Supervisão. Revisão e aprovação da versão final do trabalho.

FINANCIAMENTO

Não se aplica.

CONSENTIMENTO DE USO DE IMAGEM

Não se aplica.

APROVAÇÃO DE COMITÊ DE ÉTICA EM PESQUISA

Não se aplica. 
CONFLITO DE INTERESSES

Não há conflito de interesses.

\section{LICENÇA DE USO}

Este artigo está licenciado sob a Licença Creative Commons CC-BY. Com essa licença você pode compartilhar, adaptar, criar para qualquer fim, desde que atribua a autoria da obra.

\section{HISTÓRICO}

Recebido em: 23-04-2020

Aprovado em: 22-02-2021 